\title{
Dados etnográficos de presenças estrangeiras: intervenções de uma antropóloga no trabal ho com crianças refugiadas na Inglaterra
}

\author{
LIANA LEWIS*
}

\begin{abstract}
R esumo: A noção de ciência, como saber descomprometido, vem sendo substituída pela compreensão da necessidade de intervenção por parte dos produtores de conhecimento. Tal produção constitui-se em ato inevitavelmente político quando doservamos a vida das pessoas e as relaçães de poder que pemeiam seu cotidiano. Como resultado de um trabalho etnográfico com crianças refugiadas em uma escola na Inglaterra, discorro sobre a necessidade de um posicionamento por parte do antropólogo através da explicitação das alianças estabelecidas no campo. Acredito que tal atitude possa permitir a viabilização de intervencões a favor dos grupos estudadbs e que tal comprometimento se faz fundamental, caso o trabalho não seja caracterizado por uma atitude reprodutora de desigualdades sociais.

Palavr as-chave: ciência, relaçães sociais, poder, crianças refugiadas, racismo, altura hegemônica inglesa.
\end{abstract}

De que lado você está?

M inha decisão em iniciar este artigo, através de um questionamento que demanda claramente uma definição por parte do cientista, representa minha atitude de contraposição a qual quer resquício do mito moderno/positivista de neutralidade científica (Blair, 1998, p. 13). Seguindo o preceito pós-estruturalista e feminista de que todo saber é parcial e situado (Haraway, 1991, p. 195; L ather, 1991, p. 33), acredito ser tal mito um artifício discursivo, cuja finalidade é a dissimulação dos interesses do cientista (Gillborn, 1998, p. 47). Retornando a minha indagação, no caso do antropólogo, ela aponta não apenas para a necessidade de exposição de um posicionamento político, como também

\footnotetext{
* D outoranda na The Nottingham Trent U niversity, GrãB retanha. Mestre em A ntropologia Cultural pela Universidade Federal de Pernambuco. Bolsista da Capes - Brasília/ Brasil. E-mail: lianalew@ hotmail. com.
}

para o reconhecimento de que toda relação social é constituída pelo poder (Foucault, 1991, p. 26) e que nós estamos inseridos em uma teia prática e discursiva construída de forma desigual.

0 tradicional olhar antropológico que constitui e aprisiona o Outro no âmbito da diferença, tomando o próprio cientista como referencial de normalidade, vem sendo substituído por um olhar e uma voz críticos que identificam, explicitam e desafiam relações de dominação. Porém, o trabalho de campo suscita questões éticas e práticas quanto à linearidade das ações acima referidas. A observação participante, técnica privilegiada, tomada quase como sinônimo de antropologia, que visa apreender as dinâmicas sociais em suas sutilezas - contradições, lapsos, reproduções, redimensionamentos e rupturas - , só se faz possível quando da autorização da inserção do antropólogo no cotidiano de uma dada instituição, comunidade ou grupo. E a permanência em tais localidades 
depende, na maior parte das vezes, de uma atitude não-desafiadora em relação aos grupos e discursos dominantes.

A narrativa que será apresentada tem como objetivo relatar parte do percurso da minha pesquisa doutoral de campo, na qual a linearidade da intervenção foi algumas vezes interrompida, em prol de uma ação que visasse à promoção mais imediata do bem-estar das crianças com quem trabalhei, e outras vezes mantida, visando à continuação da observaçãoparticipante, já que explicitações e desafios podem se tornar ações disrruptivas ao longo do trabalho de campo.

\section{Introduzindo o campo}

Moulton, o local onde a pesquisa foi efetuada, é uma cidade mediana situada no leste central da Inglaterra, englobando aproximadamente trezentos mil habitantes. U ma diversidade de comidas, roupas e línguas compõem o cenário local. Europeus, asiáticos, sul-asiáticos, sul-americanos, afro-caribenhos, africanos, curdos, intersecção de diversas etnicidades dão o tom da diversidade.

U m dos fatores determinantes da composição étnica de M oulton éa política de dispersão de refugiados implementada pelo governo federal, que impõe a difusão de asilados com o pretexto de reduzir a quantidade de serviços oferecidos em Londres e no sudoeste do país. No ano 2000, M oulton ocupava a nona posição no ranking das cidades provincianas a receber a maior quantidade de asilados sob o esquema que começou a vigorar em abril do mesmo ano (M oulton R efugee A ssociation). ${ }^{1}$

A tual mente, na composição mundial, mais de dezessete milhões de pessoas são refugiadas ou asiladas (U nited $\mathrm{N}$ ations $\mathrm{High}$ Comission for Refugees). A definição de refugiado foi concebida pela Convenção das $\mathrm{N}$ ações U nidas de 1951, relativa ao Estatuto dos Refugiados, que estabeleceu o refugiado como uma pessoa que tema

1. Com o intuito de preservar a confidencialidade dos sujeitos da pesquisa, fez-se necessário alterar o nome da cidade e, por conseqüência, da ONG que trabalha com refugiados e asilados. Dessa forma, a referência bibliográfica teve de ser adulterada para seguir o padrão de discrição. ser perseguida por motivos de raça, religião, nacionalidade e que não pode, ou em virtude desse temor não quer, valer-se da proteção desse país, ou que, se não tem nacionalidade e se encontra fora do país no qual tinha sua residência habitual em conseqüência de tais acontecimentos, não pode ou, devido ao referido temor, não quer voltar a ele.

No Reino Unido, a condição de asilado é definida como al guém que está à espera de uma decisão do governo federal em relação à possibilidade de receber ou não o status de refugiado (R utter, 2001, p. 4).

$\mathrm{M}$ eu trabalho foi efetuado com crianças refugiadas e asiladas que migraram com suas famílias da área curda na Turquia, de A ngola, do Congo, do A feganistão e de Zimbabwe. A observação-participante foi realizada na Escola Primária Green Park, Iocalizada em um bairro do mesmo nome, predominantemente proletário. No B rasil, tal localidade seria comumente denominada de classe baixa ou classe média baixa. Tais bairros, social e economicamente desfavorecidos, são os locais escolhidos pelo governo para o fornecimento de moradias para os asilados, devido ao baixo preço dos aluguéis. Dessa forma, chegando na Inglaterra, tais crianças são automaticamente posicionadas como social e economicamente desavantajadas. Um dos fatores representativos do desfavorecimento da área é ela ser composta majoritariamente por asiáticos e seus descendentes, pessoas provenientes em sua maioria do Paquistão, ex-colônia britânica, que lá chegando exercem atividades relegadas às camadas mais desfavorecidas da população.

A Escola Primária Green Park concentra o maior número de crianças refugiadas da cidade. A distribuição étnica total dos estudantes é composta por cerca de $80 \%$ de crianças inglesas de descendência asiática, $16 \%$ de crianças inglesas brancas e $4 \%$ de outras nacionalidades, aqui incluindo as crianças refugiadas. Embora a instituição seja localizada em um bairro predominantemente asiático, os professores são, em sua maioria, brancos de classe média. Considero importante especificar a composição étnica e socioeconômica da escola, por acreditar que tais condições, juntamente com outros determinantes como genêro e geração, vão informar as rela- 
ções dos diversos grupos, posicionando certas pessoas como diferentes em relação a padrões de normalidade (Woodward, 1997, p. 1).

A través da observação e participação no cotidiano das salas de aula, assembléias, atividades recreacionais, conversas informais com as crianças e professores e entrevistas, busquei apreender as configurações das relações sociais estabelecidas pela presença das crianças refugiadas na instituição, como essas crianças seriam posicionadas discursivamente, bem como as percepções delas próprias em relação ao cotidiano escolar e ao novo país.

\section{A inserção através do desafio}

Em meu primeiro dia de pesquisa, Frieda, ${ }^{2}$ professora responsável pelas crianças refugiadas, introduziu-me à escola, pontuando ser 0 trabal ho na instituição bastante desafiador. Sem oferecer maiores explicações, ela observou que em outra escola, no bairro de Benington, as crianças são mais bem comportadas. Tanto Green Park, quanto B enington são dois bairros com população de baixa renda. A o comparar escolas de ambas as localidades, utilizando o comportamento das crianças como referencial, Frieda explicitou uma val oração social baseada no grau de internalização da disciplina por parte das crianças.

F az-se necessário pontuar aqui o lugar de Frieda ao longo da pesquisa e deste artigo. Como era ela a profissional que se encontrava mais comprometida em relação às crianças refugiadas e que tinha maior conhecimento destas individualmente, minhas discussões deram-se basicamente com ela. Em virtude desse contato mais próximo, Frieda foi a profissional que mais expôs (e se expôs) suas percepções, muitas vezes de caráter discriminatório. Não se trata aqui de culpabilização de indivíduos ( $\mathrm{M}$ ac an Ghaill, 1988, p. 6). As percepções de Frieda tornaram-se mais evidentes ao mesmo tempo em que ela apresentava um genuíno comprometimento em ajudar as crianças, sem saber estar, muitas vezes, promovendo a discriminação

2. Frieda é a professora responsável pelo Ethnic M inority A chievement Group, espaço institucional reservado à assistencia a crianças estrangeiras ou descendentes de estrangeiros. destas últimas através de reproduções de discursos de caráter racista.

M inha inserção na escola foi marcada por um forte impacto em relação à rígida disciplina escolar, disciplina esta que vejo não como caracteristicamente intrínseca à instituição escolar, já que toda instituição está, também, relacionada à dinâmica da sociedade mais ampla ( $M$ ac and $G$ haill, 1988, p. 64). Chegando na sala de aula, que agrupa crianças diversas, não apenas refugiadas, com idades de oito a nove anos, impressionou-me o fato de a professora, Grace ( $M$ iss C urtis), lembrar constantemente, e com voz alta e autoritária, como as crianças deveriam se comportar enquanto estão sentadas no carpete durante as lições: direcionando o olhar direta e constantemente para ela, mantendo os braços cruzados, a coluna ereta, o "bumbum" encostado no chão e sem estabel ecer nenhum tipo de conversa paralela ou comentários sem sua autorização. 0 ambiente é de total controle e formalidade, a professora é adereçada por Miss (título indicativo de autoridade geracional, já que crianças não são referidas dessa forma) e o sobrenome. A famosa "tia", forma carinhosa tão comumente utilizada nas escolas primárias no B rasil, não faz parte da lógica relacional na Inglaterra. A fetividade tem de ser, na maior parte das vezes, substituída por formal idade.

$\mathrm{Na}$ obra Discipline and punish, Foucault (1991, p. 200-201) chama-nos a atenção sobre como a disciplina organiza e caracteriza grupos de pessoas como socialmente desviantes, necessitando de controle. No caso de Green Park, a relação de poder é atualizada pela disciplina que permeia todo o cotidiano escolar, sendo entrecortada por outras relações de desigualdade, como a de gênero e a racial. Comecei a tentar vislumbrar estratégias de como desafiar a disciplina institucional, de como, através da minha presença na escola, comunicar às crianças que aquele não é o único modelo possível de relação. M as como transgredir um padrão de relação institucional sem ser disrruptiva? Como transgredir ou desafiar a cultura institucional sem que as portas de tal organização se fechem para mim?

U ma das formas de estabelecer uma aliança com as crianças foi desafiando tal 
disciplina quando possível, e de forma bastante sutil, caso contrário, o óbvio aconteceria: a instituição recusaria minha presença. Minha intervenção como pesquisadora e estrangeira foi atualizada, nesse início, de forma bastante generalizada, não sendo direcionada particularmente às crianças refugiadas, já que, nesse primeiro momento, ainda não era possível perceber qual seria o discurso e a prática da escola em relação a estas últimas.

Quando me introduziu à turma, Grace me pediu para descrever brevemente $\mathrm{o}$ B rasil. U ma das minhas observações foi de que aqui, em geral, as pessoas falam alto e expressam-se muito através do corpo durante uma conversa. Nesse momento, utilizei meu privilégio como adul ta para comunicar às crianças que é possível fazer parte de uma lógica distinta da exercida pela cultura dominante inglesa sem se considerar fora de lugar. Essa foi minha primeira estratégia para dizer às crianças que a disciplina e a formalidade britânicas me eram estranhas, que minha aliança não se daria com a cultura hegemônica.

0 fato de me apresentar de forma mais espontânea, inclusive brincando com as crianças na hora do recreio, fez com que um contato mais afetivo fosse possível. Nas semanas subseqüentes, uma cena comum era, quando da minha chegada na escola, ou durante o recreio, as crianças correrem em minha direção e me abraçarem. Tal possibilidade de contato corporal e afetividade pareceu ser viabilizada em razão do fato de as crianças perceberem que, assim como a maioria delas, venho de uma cultura bastante diferenciada da hegemônica inglesa. Durante o recreio, elas comumente perguntavam-me de onde vinha, qual a língua que falava e quais as características do Brasil.

Em nível mais generalizado, minha intervenção foi ef etuada através da afirmação de meios de comunicação e relações que percebo como constitutivas da idéia generalizada de identidade brasileira, em oposição à concepção dominante de identidade inglesa. Considero tal movimento uma atividade política, já que o encontro ou as relações culturais são tecidas através de valorações, de relações de dominação. Em relação às crianças refugiadas, as intervenções seriam mais específicas, em virtude da multifacetada constituição de suas identidades.

Desafiando o ester eótipo do garoto negro

A experiência de ser uma criança refugiada não é determinada apenas pelo evento de um deslocamento geográfico. Elas são não apenas crianças que migram de seus países em busca de refúgio. Elas são meninos e meninas, negras e brancas, elas vêm de determinadas classes sociais. Elas são transformadas em Outro de formas diferenciadas, de acordo com hierarquias específicas e as várias posicional idades de suas identidades. Elas também vão responder a tais movimentos de acordo com suas possibilidades individuais. 0 fato de não fazer parte da estrutura ocupacional escolar, bem como da cultura inglesa, possibilitou-me um distanciamento crítico no que diz respeito a tais hierarquias e ao discurso institucional em relação às crianças e às concepções hegemônicas de infância.

No meu primeiro dia de pesquisa, a professora perguntou:

Vocês acham que se vocês vêm de um país muito diferente da Inglaterra, isto faz vocês diferentes? Nós somos muito sortudos nesta escola porque nós temos pessoas diferentes. L evante a mão se você já morou num país diferente. Como ele é diferente? Pode ser através da comida, da religião, clima, montanhas.

Essa indagação constituiu-se em uma tentativa de celebração da diversidade cultural na escola, sem a professora perceber estar, na verdade, transformando al gumas crianças em Outro, posicionando-as como diferentes em relação a um referencial de normalidade: 0 inglês branco. Pessoas, elas têm diferentes cores. Tal resposta foi fornecida por A rmand, um garoto de nove anos de idade que foi do Congo para a Inglaterra morar com sua tia que lá reside há anos. Para A rmand, é evidente que sua negritude seja constitutiva das suas experiências no novo país. A diferença em seu atributo físico vai determinar a hierarquia das dinâmicas sociais.

Grace, a professora, uma inglesa branca, ignorou completamente a resposta de A rmand. 
Logo após fazer sua pergunta, ela pediu às crianças que escrevessem em um pedaço de papel o que achavam que todo mundo precisa para sobreviver e viver alegremente. A rmand escreveu: família, pais. Grace respondeu que ela estava mencionando algo, nas palavras dela, como quando você está com sede, e pediu a A rmand para apagar sua resposta. A rmand percebeu a impossibilidade de Grace em escutar suas necessidades e pediu-me que 0 auxiliasse na soletração da palavra família, adicionando essa palavra ao final da sua lista.

A razão para a migração de A rmand foi a perda de toda sua família nuclear em uma erupção vulcânica no Congo. Era explícita a impossibilidade de Grace em ver sentido ou ter empatia com sua trágica história. A o contrário, ela e outros professores interpretavam a presença de $A$ rmand na escola em termos raciais e de gênero. A pesar de A rmand ser um criança muito vivaz e ter um excel ente senso de humor, ele experienciava alguns problemas sociais e comportamentais. Durante o recreio, não tinha amigos regulares e, quando estava na sala de aula, muitas vezes transgredia as normas falando alto, quando deveria permanecer em silêncio, brincando com os colegas, quando deveria estar quieto.

E mbora A rmand não fosse a única criança a se contrapor à disciplina escolar, ele era freqüentemente o único a ser repreendido. U ma cena comum era de apenas seu nome ser mencionado quando outras crianças estavam se comportando da mesma forma. Ele era a criança a ser focada e mencionada como indisciplinada. Frieda sempre me comunicava sua desobediência e suas dificuldades de socialização. Certo dia, após escutar as correntes reclamações de Frieda em relação a A rmand, eu Ihe perguntei o que ela achava que o levava a agir de tal maneira. Ela respondeu que existe toda uma literatura relacionada ao problema do garoto negro e que muitas dessas crianças vêm de uma estrutura familiar desorganizada. De acordo com ela, os pais de tais garotos constantemente abandonam suas famílias, não propiciando uma figura masculina para eles se identificarem.

Tal representação de estrutura familiar é encontrada em uma literatura específica, relacionada às crianças afro-caribenhas, que identifica na cultura de origem a responsável pelo insucesso escolar dos garotos, ignorando ser esse insucesso resultante do racismo institucional. ${ }^{3}$ E ssa concepção de comunidade, ou de uma cultura como intrinsicamente problemática, constitui-se um recurso retórico que evita o termo raça, como significante, a fim de prevenir acusações de racismo (Solomos \& Back, 1996, p. 19). De acordo com M áirtín M ac an $\mathrm{G}$ hail, "racismo agora tende a ser racionalizado em termos de diferenças culturais ao invés de superioridade cultural" ${ }^{4}(1988$, p. 3).

Devemo-nos nos lembrar, no entanto, que A rmand não é afro-caribenho, ele é africano, e que seu pai não abandonou sua casa, el e morreu, como os outros membros de sua família nuclear. Frieda não conseguia perceber que o comportamento de Armand era decorrente de sua trágica história de vida e que ele sinalizava com um pedido de ajuda. Ela também não conseguia entendê-lo como atuando em reação ao racismo institucional, já que, conforme mencionado anteriormente, é uma prática comum entre os professores chamarem apenas sua atenção quando outras crianças estão também desafiando as regras escolares.

Ele estava sendo posicionado dentro do estereótipo do homem negro disrruptivo e potencial mente violento. Quando ele deixou a escola para ir morar em outro bairro, ${ }^{5}$ uma área predominantemente afro-caribenha e conhecida na cidade como local de diversos assaltos e tráfico de drogas, Frieda manifestou sua preocupação com ele, pois, para ela, A rmand podia, no futuro, juntar-se a uma das gangues. Vale lembrar que A rmand tinha, então, apenas nove anos de idade e que nunca havia apresentado nenhum comportamento violento.

Enquanto os professores desconsideravam sua história de vida, as crianças se apropriavam desta de uma forma bastante cruel. E m um dado

\footnotetext{
3. Existe uma vasta literatura etnográfica atestando o caráter discriminatório da instituição escolar inglesa em relacão às crianças negras, principalmentes do sexo masculino. Ver Blair, 1998; Connolly,1998; Gillborn, 1998; M ac an Ghail, 1988; Williams, 1995; W right, 1992.

4. Tradução da autora.

5. $\mathrm{Na}$ Inglaterra, as crianças que fazem parte da rede pública de ensino são direcionadas às escolas mais próximas do local de residência.
} 
momento, A rmand confidenciou a um colega de turma a forma como seu pai morreu. Essa criança tornou público o segredo de A rmand, fazendo piadas sobre sua situação durante a hora do almoço, quando todas as crianças encontravam-se reunidas. A rmand pareceu perceber suas dificuldades em socializar como um problema racial. U ma vez, ele disse-me, em tom de brincadeira, que gostaria de pintar sua pele de branco. Quando Ihe perguntei o porquê, ele respondeu:

Se eu pintar minha pele, se eu me tornar branco, eu posso ir para, hum... Se eu me tornar uma nova pessoa. Então eu, eu sei agora. Eu digo isto porque eu quero, eu quero ter muitos amigos.

D urante a semana que sucedeu à revelação pública de sua história de vida, A rmand foi constantemente repreendido por M ark, 0 professor estagiário que permanecia impassível aos choros da criança. M esmo tendo conhecimento do ocorrido na semana anterior e do fato de algumas crianças terem desdenhando da dolorosa experiência de A rmand, $M$ ark ignorou completamente a expressão de sentimento do menino, que eu percebi como uma súplica por auxílio.

A proximei-me de A rmand para consolá-lo e ele retrucou: "Eu quero voltar pra casa. Eu quero voltar pra Á frica". A pesar de não experimentar a discriminção de raça associada ao genêro, como ocorre com A rmand, tentei al guma empatia com sua dor, através das nossas experiências comuns como estrangeiros. DisseIhe imaginar o quanto devia ser difícil para ele se adaptar à vida na Inglaterra, ${ }^{6}$ mas já que ele estava lá deveria tentar fazer o mel hor possível. A pesar de saber que estava solicitando muito a uma criança de apenas nove anos, que se encontrava em situação de tamanha vulnerabilidade, achei necessário deixar claro para ele que sua perspectiva de vida no novo país iria depender, também, de um esforço da parte dele, já que o racismo institucional opera contra os garotos negros, visando a seu insucesso.

6. Essa declaração não foi guiada por uma mera tentativa de empatia, mas pela lembrança do meu processo de angústia quando da chegada no país.
Quando perguntei a Frieda o que considerava como causa para o comportamento de A rmand, ela respondeu-me com base em um conhecimento científico que legitima o racismo institucional, através da abstenção do registro dos mecanismos de atuação dessa discriminação. Em seguida, ela quis saber a minha opinião. Este foi um momento crucial no desenvolvimento da pesquisa. Pois adotar a estratégia de atuação proposta por mim no início deste texto seria desaconselhável naquele momento. Estando apenas no início do trabal ho de campo, não havia colhido ainda dados suficientes em relação ao racismo institucional. A ssim, explicitar minha opinião naquela fase interferiria na forma como os membros da instituição tratavam as crianças na minha presença e, conseqüentemente, comprometeria uma apreensão mais sutil da dinâmica institucional.

Este se tornou o momento de meias verdades. A proveitando da minha formação como psicóloga, e do fato de Frieda considerar-me como uma espécie de conselheira em relação às crianças refugiadas, disse-Ihe que achava que o comportamento de A rmand era decorrente da sua história de vida, e que sua constante demanda de atenção constituía-se em um pedido de ajuda, sendo aconselhável a intervenção de um profissional da área de psicologia, o que ocasionalmente acabou acontecendo. Essa situação configurou-se como um dos momentos de maior angústia e dilema ético do trabalho de campo. Explicitar o impacto do racismo institucional em relação a A rmand interferiria de forma direta na dinâmica institucional. M inha imagem diante dos outros professores poderia tornar-se comprometida e, conseqüentemente, minha presença na instituição questionada. Nesse momento, a produção do saber (identificação das dinâmicas sociais) se sobrepôs a atitudes mais imediatistas (explicitação e desafio). Este foi o momento de ruptura entre conhecimento e ativismo. Porém, a íntima conexão de ambos poderá ser restaurada ao final da pesquisa.

\section{Um novo nome, uma nova cor}

0 racismo institucional opera de formas diferenciadas em relação às crianças refugiadas. No que diz respeito à criança negra, ele é 
perpassado pelas relações de gênero. Enquanto A rmand percebe a impossibilidade da sua integração como conseqüência do racismo institucional, a garota negra vai estabelecer um compromisso com o mundo branco através de uma atitude assimiladora, como pode ser visto na experiência de $M$ ariana.

M ariana, oito anos de idade, foi de A ngola para a Inglaterra com sua mãe e duas irmãs adolescentes. Durante as observações de sala de aula, percebi que a professora e as crianças estavam angl icizando seu nome, chamando-a de $M$ ary. Perguntei-Ihe como e quando as pessoas começaram a se referir a ela por esse nome e ela respondeu que, no primeiro dia de aula, a professora perguntou-Ihe através de qual designação ela gostaria de ser chamada: M ariana ou $\mathrm{M}$ ary? $\mathrm{E}$ ela respondeu que era por $\mathrm{M}$ ary. $\mathrm{Eu}$ perguntei-Ihe, então, o porquê de tal escolha. Ela respondeu que $M$ ary era "melhor e mais bonito". Em outra ocasião, ela pontuou: "A qui em casa as pessoas me chamam de M ariana, na escola, as pessoas me chamam de M ary".

D efato, na escola M ariana tornou-se $M$ ary. Ela internalizou a rígida disci plina institucional, considerada por mim como o principal ethos escolar. Sempre respondia aos comandos da professora com uma expressão extremamente séria e postura rígida. Ela internalizou a disciplina escolar a ponto de reproduzi-la para outras crianças, ordenando-Ihes para se comportarem quando estas não atendiam às expectativas da professora. Em contraste, quando estava em casa, M ariana era extremamente vivaz e carinhosa.

A representação desse duplo papel, sinalizador de uma dupla consciência, sendo M ary na escola e $M$ ariana em casa, parece ser uma conseqüência de uma entrada mais ef etiva no mundo branco. Esta é uma das suas estratégias de sobrevivência. No livro Black skin, white masks, Frantz Fanon faz uma análise da constituição da subjetividade do homem negro como resultado do encontro colonial. Conclui que, como conseqüência da violência colonial, a branquitude tornou-se a norma. Em suas palavras: "Para o homem negro existe apenas um destino. E ele é branco"7 (1986, p. 12).

7. Tradução da autora.
Todo processo de internalização é decorrente de uma identificação, de um desejo de ocupar o lugar do outro. No caso de M ariana, 0 corpo da mulher branca é o corpo desejável. D urante o processo de entrevista, ela foi a única criança que qualificou a professora em termos de corpo. Quando perguntei-Ihe o que ela achava de Grace, sua professora, ela primeiramente respondeu: "B onita". D urante uma das atividades de arte, $M$ ariana desenhou três garotas e uma mulher de pele branca e cabelos loiros. Temendo ser aquel a uma versão embranquecida da sua familia nuclear, perguntei-Ihe quem eram tais pessoas. 0 meu temor foi confirmado quando ela respondeu serem ela, sua mãe e duas irmãs. Eu chamei a atenção para 0 fato de as pessoas no desenho serem brancas. Ela disse: "Quando estavámos em Angola nós éramos morenas, mas desde que chegamos na Inglaterra nós estamos nos tornando brancas". Ela parecia internalizar a noção de ser sua cor considerada fora de ordem. De fato, para M ariana, o destino era branco.

Branco é o destino, porque branco é a norma. Nenhuma das professoras presentes observou o desenho de $M$ ariana, e sua negritude teria "passado completamente em branco" caso eu não tivesse interferido, fazendo comentários positivos em relação a sua cor e à importância de assumirmos quem somos. Porém, a afirmação da cor negra torna-se tarefa difícil quando o olhar branco nega sua capacidade de representação.

Em certa ocasião, Frieda mostrou-me um desenho elaborado por M alaika, uma garota proveniente do Zimbábue. Com expressão apreensiva, ela observou serem todas as pessoas representadas através da cor preta. A intenção de Frieda era de que eu analisasse 0 desenho, com base na minha formação de psicóloga, sugerindo que a cor preta apresentava-se como sinal de algo fora de ordem, de al gum sintoma que necessitasse ser restituído pelo olhar do branco. Explicitei não perceber 0 que podia haver de errado em al guém representar em seus desenhos indivíduos negros, principalmente sendo a própria pessoa que elabora o desenho negra. Frieda concordou e permaneceu em silêncio com um olhar pensativo. Essa atitude de sutil desafio em relação às concepções 
racistas de $F$ rieda repetiu-se ao longo da minha permanência em campo e acredito terem propiciado oportunidades de reflexão sobre um discurso que permeia a instituição, posicionando os indivíduos através de dualidades de cores.

\section{Quais corpos são importantes?}

$M$ alaika, nove anos de idade, migrou do Zimbábue para a Inglaterra, com suas irmãs mais velhas (ambos os pais de $M$ alaika estão mortos). A primeira vez que a vi, percebi ser seu corpo muito menor do que os das crianças da sua turma, apesar do fato de ela ser a mais vel ha. M alaika era extremamente magra, a pele ressecada e os dentes visivelmente danificados, sendo alguns erodidos e de cor enegrecida. Quando me falava de M alaika, Frieda comentava sobre a vulnerabilidade em que ela se encontrava, já que sua irmã mais velha, com apenas 21 anos de idade, já tinha um filho recémnascido. 0 corpo de $M$ alaika era a expressão materializada de uma criança que necessitava de cuidados mais efetivos. E ela era muito consciente da sua estética corporal.

Durante uma das assembléias, ela defrontou-se com a diferença no cuidado do seu corpo, em relação ao restante das crianças da escola. 0 tema da reunião era a Semana Nacional do Sorriso, e a professora que coordenava o evento fal ava da importância do cuidado com os dentes para a apresentação de um belo sorriso. Ela, então, pediu às crianças para mostrarem o quão bonitos eram seus sorrisos. M alaika parecia ser a única criança que não sorria, apresentando uma expressão constrangida. Durante o intervalo, fui para a sala dos professores e observei que a professora coordenadora da assembléia descrevia o ocorrido com Malaika, rindo da situação. Frieda e Grace juntaram-se a ela e também divertiam-se com o ocorrido. U ma das professoras comentou ter sido a escola considerada pelo Sistema N acional de Saúde como uma das piores, em Moulton, quanto à saúde bucal das crianças. F rieda deu uma contribuição à atmosfera bizarramente divertida: ela observou que os dentes de Hiwa, outro garoto refugiado, eram amarelos. Grace fez uma expressão de asco e pediu para que as professoras finalizassem os comentários, não pelo absurdo e pela falta de respeito, mas por ela estar fazendo sua refeição.

M inha presença na sala dos professores sempre deu-se de forma bastante discreta. A pouca interação era devida, por um lado, a razões diversas, como não estar diariamente na instituição, não fazer parte do corpo de funcionários e pelo caráter reservado da maior parte dos ingleses. Por outro lado, optei por um distanciamento para que os profissionais pudessem interagir de forma mais espontânea, como aconteceu no evento acima descrito.

Interessante enfatizar que as crianças tornadas visíveis pelas professoras eram ambas refugiadas. A sala dos professores funciona como espaço revelador das percepções de distinções não apenas de geração, mas também de cor, classe social e pertencimento cultural. A diferenciação das crianças refugiadas é feita não apenas pelas professoras, como pelo restante da escola e mesmo da cidade, onde tal insti tuição apresenta-se como a mais vul nerável em relação à saúde bucal das crianças. A través da competência e aparência corporal, signos de normalidade, as crianças refugiadas tornam-se os 0 utros em relação à totalidade da escola e à sociedade mais abrangente.

Em seu livro Purity and danger (1994), $M$ ary Douglas postula que as relações em determinadas sociedades são organizadas através da dicotomia pureza $x$ poluição ritual. Sendo a noção de poluição anál oga a uma visão da desordem social, separar, punir, purificar são ações sistematizadoras de uma experiência desordenada. É por meio da separação que a ordem é estabelecida. A o observar que, na sociedade ocidental, a i déia de limpeza é anterior à descoberta da transmissão bacteriana ocorrida no século XIX, D ouglas pontua que aqui a idéia de pureza não indica meramente um cuidado com a higiene, mas um respeito pelas convenções, pela ordem (Douglas, 1994, p. 36). A autora conclui que a base da idéia de pureza é uma concepção simbólica, como ocorre com a poluição ritual nas sociedades ditas tradicionais. A concepção de poluição está estritamente vinculada à idéia de moral, já que a integridade da estrutura social é questionada quando ocorrem transgressões. Se estas acontecem, em 
contrapartida, a sociedade adota medidas coercitivas.

Rodrigues observa que a noção de impureza não apenas ordena a sociedade, como estabelece relações de hierarquia. Segundo 0 autor:

Quanto mais próximo do centro do poder, mais distante da poluição; quanto mais periférico em relação ao centro do poder, tanto mais íntimo da sujeira ou do lixo. Nunca há definição de' impuro' sem a existência de um poder que se queira próximo ao puro e que defina uma hierarquia com base em sua posição. (1999, p. 92)

$\mathrm{N}$ a minha volta à escola, após o incidente mencionado acima, expressei a Frieda minha preocupação em relação à saúde das crianças refugiadas. Disse-Ihe da minha percepção em rel ação à vulnerabilidade corporal de M alaika e indaguei sobre qual seria a responsabilidade da escola em relação a ela, já que a família demonstrava uma clara impossibilidade de lhe atribuir maiores cuidados. Frieda assinalou que - Sistema Nacional de Saúde trabalhava de forma independente em relação à escola, tendo procedimentos particulares. Em uma sociedade rigidamente burocratizada, as especificidades individuais são ignoradas pelas regras institucionais. A única possibilidade de intervenção vislumbrada por Frieda foi quanto à assistência psicológica em relação a A rmand. Ela lembrou o fato de que a A utoridade Educacional L ocal - equival ente à Secretaria de Educação - cortou verbas para o trabalho com crianças de minorias étnicas e, por conseqüência, refugiadas. Ficava exposto, assim, que essas crianças estavam suscetíveis não apenas ao racismo e descaso institucional, mas também reféns de políticas públicas excludentes.

Logo após minha conversa com Frieda, expus minha preocupação a Grace, professora de M al aika. Esta agradeceu minha intervenção, seguindo os predicamentos de ritualização da educação inglesa, e observou que havia al gum tempo, M alaika estava tomando medicação. Ela pontuou também ser difícil para ela dar conta dos problemas das crianças individualmente, já que trabal hava com trinta alunos na sal a de aula.
A fala de Grace apresentava-se de forma contraditória. Ela estava ciente da condição de saúde física de Malaika, já que demonstrava saber do fato de ela ter estado em medicação há al gum tempo, mas, apesar disto, não interferiu de forma a interromper as zombarias que aconteceram na sala dos professores sobre a aparência dentária de M alaika.

U ma semana e meia após tal intervenção, chegou ao meu conhecimento que $\mathrm{M}$ alaika encontrava-se hospitalizada, em conseqüência de problemas respiratórios. 0 médico sugeriu que a escola lhe fornecesse leite diariamente. Parecia que a hospitalização era resultante de problemas de caráter nutricional, algo que acredito pudesse ter sido evitado, caso a instituição tivesse assumido responsabilidade em relação a sua saúde, cuja debilidade era visível ao primeiro olhar que se direcionava ao seu corpo. A o que tudo indicava, o corpo de M al aika não importava muito. A vulnerabilidade de um corpo negro, africano, que busca refúgio, não é apreendida como uma situação de risco infantil, pois não segue os predicamentos da concepção ideal de infância veiculada pelos tablóides ingleses. N esse caso, a vulnerabilidade infantil é prioritariamente representada por fotos de crianças inglesas, brancas de cabel os loiros, que são arrancadas por um pedófilo do âmbito de uma família nuclear idealizada. A s experiências e as histórias de vida das crianças refugiadas são ignoradas, desinvestidas por uma sociedade que relembra constantemente, por meio dos programas televisivos, as glórias da época do império, desconsiderando ainda hoje as pessoas que são vítimas e herdeiras das conseqüências de tal dominação.

\section{O que a escola pensa disto tudo?}

Uma teia discursiva que se materializa, através de práticas cotidianas, constitui-se em resposta da Escola Primária Green Park, em relação à presença das crianças refugiadas. Tanto no primeiro dia de pesquisa, quanto durante a entrevista, Frieda disse-me que a escola era bastante adequada à presença das crianças refugiadas, em virtude de seu ethos multiculturalista. 
A iniciativa multicultural ista que surgiu na Inglaterra, na década de 1970, é baseada na concepção de igualdade de oportunidades entre os estudantes, sem levar em considerção as disparidades presentes nas relações institucionais e da sociedade mais ampla, como classe, gênero e cor (Troyna, 1992, p. 69). Esse paradigma entende ser preconceito o resultado de ignorância e prescreve como solução o saber curricular de "outras culturas" (R attansi, 1992, p. 28). Dessa forma, o multiculturalismo celebra a diversidade, estagnando as pessoas em suas "diferenças", sem perceber como essas diferenças são construídas, bem como as práticas cotidianas de exclusão. A ndando pelos corredores da escola e observando a decoração das salas de aula, percebi um esforço por parte da instituição em promover a perspectiva multiculturalista. A presença de livros infantis em diversas línguas, fotos de mesquitas, artistas negros, crianças africanas parece ser um esforço institucional em enviar a mensagem "todo mundo importa", sem levar em consideração as hierarquias estabelecidas entre as pessoas que essas figuras representam e a cultura hegemônica.

A rmand e $M$ alaika sabiam que as pessoas não importam da mesma forma. Em relação a eles, existe na escola uma hierarquia de diferenças baseada em cor, gênero e país de origem. A s diferenças são atravessadas por valorações e graus de exotismo, tendo a cultura inglesa branca como referencial de normalidade. Em uma das aulas, Grace contou a história de um garoto inglês branco que vai para um país, em suas palavras, muito exótico. A pós apresentar diversos estereóti pos de tal local idade, ela pediu para as crianças adivinharem a qual país a história se refere. Quando uma criança respondeu Israel (país bastante ocidentalizado), ela permaneceu em silêncio. Outra criança citou Á frica, e ela pontuou a resposta como uma "boa tentativa". U ma próxima criança respondeu China, ela retrucou "não" eforneceu a resposta.

A lém de não explicar que a Á frica era um continente e não um país, Grace reforçou a noção de que essa localidade era mais exótica em relação aos outros exemplos fornecidos pelas crianças. A sua pontuação "boa tentativa" foi direcionada apenas à Á frica. Em relação a
Israel e China, ela não emitiu nenhuma observação. Posicionando-se apenas em relação à A frica, Grace transmitiu às crianças a idéia de que esse continente é mais diferente na hierarquia dos Outros, ocupando uma posição mais elevada na escala de exotismo geográfico e cultural. A resposta institucional - a cor, gênero e país de origem de A rmand e $M$ alaika - tornou evidente que o multiculturalismo é um mito benevolente que mascara as diversas desigual dades impostas a essas crianças. Diferentemente do que postula esse paradigma, as culturas não são percebidas apenas como diferentes entre si, mas diferentes em relação a um padrão de normalidade, nesse caso, a cultura inglesa.

0 ethos escolar não se apresenta de forma uniforme, através de um discurso único. Discursos contraditórios muitas vezes coexistem no mesmo espaço institucional, atestando o caráter multifacetado das relações sociais. Paralelamente à concepção multiculturalista, observamos atitudes assimilacionistas baseadas no paradigma monoculturalista, que visa à anulação de diferenças étnicas, culturais e lingüísticas (Troyna, 1992, p. 68). A efetivação desse paradigma fez-se explícita quando a escola ofereceu a M ariana a possibilidade de escolha de um nome inglês. É como se estivessem Ihe perguntando: "você quer se tornar uma de nós, ou continuar sendo você?". Diante das pressões e privilégios do mundo branco, M ariana optou por fazer uma aliança com a cultura hegemônica, anglicizando-se.

A dicional ao fato de evitar o reconhecimento do racismo institucional, a escola é atravessada pelo discurso da inocência infantil. Tal discurso, bastante corrente na atualidade, é herdeiro da noção rousseauniana de ser humano. Para R ousseau, o homem nasce desprovido dos mal efícios da civilização, para ser posteriormente corrompido por esta: "O homem nasce livre; e em toda parte ele se encontra acorrentado" 8 (Rousseau, apud J ames, J enks e Prout, 2001, p. 13). Dessa forma a criança é concebida como naturalmente boa, devendo suas características servirem como model os a serem seguidos pel os adultos (James, Jenks e Prout, 2001, p. 13). Sendo guiada por tal concepção de infância, a

8. Tradução da autora. 
instituição desconsidera 0 fato de as crianças serem seres sociais. Fazendo parte ativamente de uma comunidade, a criança tem suas ferramentas conceituais marcadas pelas idéias dominantes, incluindo racismo e suas expressões. Quando perguntei a M r. Williams, um dos professores da escola, sobre as percepções das crianças em geral em relação às crianças refugiadas, ele respondeu que, além de a maior parte das crianças na escola também vir de diversas origens étnicas, elas absolutamente ignoravam qualquer sinal de diferenciação.

Entendo que as dificuldades de a escola em lidar com tais situações são resultado da sua incapaciadde em reconhecer e combater 0 próprio racismo institucional, através da adoção de uma perspectiva anti-racista, que também daria conta de outras fontes de diferenciação social. A escola é guiada por outras estruturas discursivas, como multicultural ismo, assimilacionismo e o mito da inocência infantil. A ssim, a instituição falha em reconhecer as diversas formas discriminatórias como as crianças refugiadas são dirigidas. Para combater 0 racismo, faz-se necessário seu reconhecimento no âmago das instituições, identificando suas multifacetadas formas de expressão.

\section{Tomando partido}

A explicitação do posicionamento do antropólogo em relação aos sujeitos da pesquisa representa o primeiro passo para a politização do trabalho de campo. 0 vetor orientador do olhar do cientista deve ser a identificação das múltiplas formas de exercício do poder, para que este tenha a possibilidade de desconstruir mitos eintervir a favor dos grupos estudados. D urante a negociação sobre viabilização da pesquisa, ficou estabel ecido entre mim e F rieda que, finda a análise dos resultados, daria um retorno à instituição. Este será o momento de desvelamento do que percebi serem as diversas formas como a instituição transforma as crianças refugiadas em Outro e da possibilidade de construção de al gumas estatégias de intervenção.

A pesar de a pesquisa não ter a intenção de generalização, acredito que possa suscitar um olhar mais crítico entre os que trabal ham com as crianças refugiadas. Como o saber deve se tornar ação e transformação, proponho-me a fornecer os dados não só para a escola, como também para os diversos setores da sociedade relacionados a tais crianças - A utoridades Eucacionais Locais, organizações não-governamentais, outras instituições escolares, bem como pesquisadores da área. Espero, assim, que novas teias possam ser construídas por meio de saberes mais justos que desafiem poderes estabelecidos.

\footnotetext{
A bstract: The notion of science as an dojective knowledge has been replaced by an understanding of the necessity of an intervention on the part of the producers of such knowledge. This production is an inevitably political act when we observe people's lives and the power relations that traverse their quotidian. As a result of ethnographic work carried out with refugee diildren in a school in England, I consider the necessity of a position on the part of the anthropologist through the clarification of the alliances established in the field. I believe that such attitude can allow the feasibility of some interventions in favour of the studied groups and that such a compromise is made fundamental in ensuring that our work is not characterized by an attitude that reproduce social inequalities.
}

K ey-words: Science, social relations, power, refugee children, racism, English hegemonic culture.

\section{R eferências}

BLA IR, M aud. The myth of neutrality in educational research. In: CONNOLLY, Paul; TORY NA, B arry (Eds.). Researching racism in education. Buckingham: O pen U niversity Press, 1998.

CON N OLLY, Paul. Racism, gender, identities and young children - Social relations in a multi-ethnic, inner-city primary school. London/New York: Routledge, 1998.

DOU GLAS, M ary. P urity and danger - A $n$ analysis of the concepts of pollution and taboo. London: Routledge, 1994.

FA N ON, Frantz. Black skin, white masks. London: Pluto Press, 1986.

FOU CA ULT, M ichel. Discipline and punish - The birth of the prision. London: Penguin B ooks, 1991.

GILLBORN, David. Racism and the politics of qualitative research: learning from controversy and critique. In: CON NOLLY, Paul; TORY NA, Barry (Eds.). Researching racism in education. Buckingham: O pen University Press, 1998. 
HARAWAY, Donna J. Simians, cyborgs and women - The reinvention of nature. London: Routledge, 1991.

JAMES, Allison; JENKS, Chris; PROUT, Alan. Theorising childhood. Cambridge: Polity Press, 2001.

LATHER, Patti. Getting smart - feminist research and pedagogy with/in the posmodern. New York/ London: Routledge, 1991.

MAC AN GHAILL, Máirtín. Young, gifted and black. M ilton Keynes: O pen U niversity Press, 1988.

NA ÇÕES UNIDA S. C onvenção das Nações U nidas de 1951, relativa ao Estatuto dos Refugiados. In: http://onu-brasil.org.br.

RATTANSI, Ali. Changing the subject? Racism, culture and education. In: DONALD, J ames; RATTANSI, Ali. 'Race', culture and difference. London/California/New Delhi: Sage Publications Ltd., 1992.

RODRIGUES, J osé Carlos. Ensaios em antropologia do poder. Rio de J aneiro: Terra N ova Editora, 1992.

RUTTER, Jil. Supporting refugee children in $21^{\text {st }}$ century Britain - A compendium of essential information. Stoke on Trent/Sterling: Trentham B ooks, 2001.

SOL OM OS, John; B A CK , Les. Racism and society. London: M acM illan Press L td., 1996.
TR OY NA , B arry. Can you see the join? A historical analysis of multicultural and antiracist education policies. In: GILL, Dawn; M AY OR, Barbara; BLA IR, $M$ aud. Racism and education - structures and strategies. L ondon/N ewbury Park/N ew Delhi: Sage Publications and The O pen University, 1992.

UNITED NATIONS HIGH COMISSION FOR REFUGEES - UNHCR. In: http://www.unhcr.ch.

WILLIA M S, Claudette. How black children might survive education. In: GRIFFITHS, M orwenna; TROY NA, Barry (Eds.). Antiracism, culture and social justice in education. London: Trentham B ooks L imited, 1995.

W OODWA RD, Kathryn. Concepts of identity and difference. In: W OODWA RD, Kathryn (Ed.). Identity and difference. L ondon/Thousand Oaks/N ew Delhi: Sage Publications and The O pen U niversity, 1997.

WRIGHT, Cecile. Multiracial primary school classrooms. In: GILL, Dawn; M AY OR, B arbara; $B L A I R, M$ aud. Racism and education - Structures and strategies. London/N ew bury Park/N ew D elhi: Sage Publications and The O pen U niversity, 1992.

ReCEBIDO EM MAIO DE 2004 A provado em Setembro de 2004 